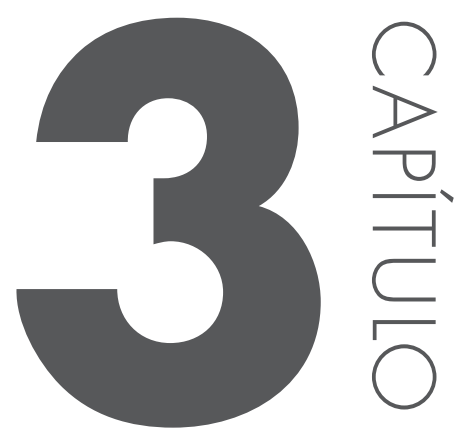

\title{
ENTRAVES AO ESTABELECIMENTO DE ACORDOS MULTILATERAIS NO ÂMBITO DA OMC
}

Taís Cristina de Menezes '; Eduardo Luiz Machado 2

' Aluna de graduação do curso de Ciências Econômicas da Universidade Federal de São Paulo (UNIFESP). Contato: tatacristinamenezes@hotmail.com.

2 Professor adjunto e coordenador do curso de Ciências Econômicas da Universidade Federal de São Paulo (UNIFESP) Pesquisador do Instituto de Pesquisas Tecnológicas.

Contato: emachado@unifesp.br.

\section{RESUMO}

Em um momento de crise do multilateralismo, a OMC lançou a Rodada Doha na tentativa de fortalecer seu sistema comercial. No entanto, a nova rodada iniciou uma sequência de impasses que resultou no enfraquecimento das negociações comerciais multilaterais. Embora Doha tenha inovado em alguns aspectos da sua agenda, como o enfoque no desenvolvimento econômico e social de países não desenvolvidos, sua realidade é de grandes divergências nas negociações, sendo estas paralisadas por diversas vezes. $\mathrm{Na}$ tentativa de dinamizar o comércio, os países passaram a buscar com maior frequência acordos preferenciais bilaterais e regionais, deteriorando o já debilitado multilateralismo. A crise financeira mundial de 2007 agravou essa conjuntura. 
Por outro lado, a eleição de um brasileiro para o cargo de diretor geral, em 2013, e a realização, relativamente, bem sucedida da Conferência Ministerial de Bali talvez sejam o começo do reestabelecimento de Doha. A partir de pesquisa documental, revisão bibliográfica e entrevistas, este trabalho procura explicar como se chegou a esta situação nas vias multilaterais de comércio, elencando e discutindo suas causas e consequências.

Palavras-chave: Comércio Internacional; Multilateralismo; Rodada Doha; OMC. 


\section{INTRODUC̣ÃO}

Ao longo das últimas décadas, a importância do comércio internacional foi crescente, em consequência do acelerado processo de globalização e integração das diversas economias mundiais. Essa ascensão da atividade comercial transformou a economia global em uma estrutura altamente complexa, com vultosas mudanças nos processos de produção e distribuição.Neste processo surgiram diferentes formas de lidar com as relações comerciais entre os vários entes, países e instituições que negociam entre si. Uma delas pode ser definida pela consolidação de acordos multilaterais.

O sistema multilateral de comércio surgiu com os objetivos de impulsionar a liberalização comercial e de regular as relações comerciais internacionais. Até 1994, o GATT (Acordo Geral sobre Tarifas e Comércio) era responsável por promover esses objetivos. Em 1995, com a criação da OMC (Organização Mundial do Comércio), a instituição passou a assumi-los (WTO, 2014).

O regime de comércio multilateral engendrado pela OMC está inserido em um contexto amplo, caracterizado pela "[...] intensificação dos vínculos entre os diversos atores internacionais, pela aproximação dos Estados em prol da busca de interesses comuns e, particularmente, pela formação de instituições multilaterais de governança econômica" (PRAZERES, 2008, p. 37).

Com o passar dos anos, pôde-se observar que, no processo de negociações multilaterais, houve o envolvimento de um número cada vez maior de países e que a abrangência sobre o volume de comércio mundial mostrou-se crescente. Sendo assim, as negociações comerciais dentro do regime multilateral tornaramse mais amplas e complexas ao longo do tempo (PRAZERES, 2008, p. 62).

O grande problema reside no fato de que o multilateralismo tem enfrentado grandes dificuldades para alcançar seus objetivos, pois o estabelecimento de acordos nessa esfera tornou-se cada vez menos frequente nas últimas décadas.

Sendo assim, o objetivo deste trabalho é analisar e compreender os motivos que provocam dificuldades em se estabelecer acordos multilaterais no âmbito da OMC, evidenciando-se a 00previsto. Também foram realizadas entrevistas para complementar as informações encontradas na revisão bibliográfica e para ajudar na formação da conclusão.

\section{MÉTODO}

Empregou-se o método qualitativo de pesquisa, com a importante característica de oferecer descrições ricas e bem fundamentadas e explicações sobre processos 
em contextos reconhecíveis (VIEIRA; ZOUAIN, 2006, p. 18). A pesquisa qualitativa constitui-se de "[...] descrições, compreensões, interpretações e análises de informações e fatos, ocorrências, evidências que naturalmente não são expressas por dados e números" (MARTINS; THEÓPHILO, 2009, p. 135).

É importante ressaltar que a pesquisa ocorreu na forma seccional com perspectiva longitudinal, ou seja, uma pesquisa na qual a coleta de dados é feita em um determinado momento, mas resgata dados e informações de outros períodos passados; o foco está no fenômeno e na forma como se caracteriza no momento da coleta, e os dados resgatados do passado são utilizados para explicar a configuração atual do fenômeno (VIEIRA. ZOUAIN, 2006, p. 21).

Inicialmente, foi feita uma pesquisa bibliográfica, que "[...] busca conhecer, analisar e explicar contribuições sobre determinado assunto, tema ou problema" (MARTINS; THEÓPHILO, 2009, p. 54).Além disso, foi realizada uma pesquisa documental - que é, segundo Martins e Theóphilo (2009, p. 55), “[...] característica dos estudos que utilizam documentos como fonte de dados, informações e evidências; os documentos são dos mais variados tipos, escritos ou não".

Também foram feitas entrevistas com indivíduos que atuam nos ramos de comércio exterior, economia internacional e relações internacionais - com o intuito de melhorar o entendimento da relação entre as diversas variáveis correlacionadas ao problema proposto e de levantar mais informações que pudessem auxiliar nas conclusões finais. Estas entrevistas foram realizadas a partir de perguntas formuladas pelos pesquisadores derivadas do conhecimento adquirido com a pesquisa bibliográfica.

\section{O LANÇAMENTO DA RODADA DOHA}

Em uma tentativa de fortalecer o regime de comércio multilateral, a OMC lançou a Rodada Doha em 2001 - sob uma pressão exercida, em certa medida, por parte dos Estados Unidos (que vivenciavam um clima político de tensão após os ataques terroristas de setembro do mesmo ano) (PRADO, 2007, p. 7).

[Houve] maior determinação dos EUA em lançar uma nova rodada, para provar que os acontecimentos [do onze de setembro] não inibiram sua capacidade de promover e atingir o objetivo da liberalização comercial, o que teria refletido sobre o posicionamento dos outros países que os teriam acompanhado e sido mais flexíveis em Doha (WEBER, 2009, p. 276). 
Embora não houvesse consenso entre os membros da OMC sobre a conveniência de iniciar uma nova rodada, a Rodada Doha foi aprovada, principalmente, em função da insistência e pressão política dos países industrializados representados pelos EUA, Canadá, Japão e União Europeia, grupo conhecido como "Quadrilátero" (JAKOBSEN, 2008, p. 8).

$\mathrm{Na}$ Declaração Ministerial de Doha, os países em desenvolvimento asseguraram um papel de destaque nas futuras negociações de comércio multilateral por meio do conceito de desenvolvimento. Ou seja, a partir daquele momento, o comércio internacional deveria desempenhar um papel importante na promoção do desenvolvimento econômico (WEBER, 2009, p. 277).

A Rodada Doha foi lançada com o propósito de efetuar mudanças no regime de comércio em vigor. Ao ser lançada em 2001, o entendimento era o de que algumas oportunidades comerciais deveriam ser melhor aproveitadas e que, para isso, certas regras e normas deveriam ser adequadas ao quadro geral das forças que impulsionavam o crescimento da economia cada vez mais globalizada. Entre as motivações da Rodada Doha também estava a ideia de que a importância relativa das economias havia mudado e que o sistema multilateral de comércio deveria refletir essas mudanças. Em resumo, em 2001, a presunção era a de que o regime de comércio vigente deveria ser mudado. Ao longo de uma década, no entanto, a Rodada Doha passou de um impasse para outro sem que qualquer resultado concreto pudesse ser efetivamente alcançado. A crise desencadeada em 2008 retirou de vez o interesse pelos destinos da rodada (SATO, 2012).

\section{IMPASSES NO SISTEMA MULTILATERAL DE COMÉRCIO}

O que parecia a solução tornou-se a extensão de um problema já decorrente. Em um momento de crise do multilateralismo, a OMC lançou Doha na tentativa de fortalecer seu sistema comercial; no entanto, a nova rodada iniciou uma sequência de impasses que resultou em um maior enfraquecimento das negociações comerciais multilaterais. Doha chegou a ser chamada de "Rodada do Milênio", entretanto, seguidas crises não tardaram a se apresentar e as negociações foram paralisadas em diversos momentos (RIBEIRO, 2007, p. 21). 
Os países em desenvolvimento passaram a defender seus interesses com maior veemência, desafiando a até então existente hegemonia norte-americana e europeia. "A mudança de paradigma, que ocorreu a partir da Rodada de Doha [...], só foi possível graças a uma intensa articulação dos países em desenvolvimento para formar coalizões fortes que pudessem se contrapor ao poder dos países desenvolvidos” (DOMINGUES, 2013).

Além dos desafios encontrados durante a Rodada Doha, pode-se observar que, na conjuntura século XXI, “[...] as fragmentações do sistema têm gerado impactos sobre a eficiência do multilateralismo, como a demanda por sua reforma e o surgimento de novos atores e canais de negociação" (PECEQUILO, 2012, p. 248).

A economia internacional, ao expandir suas dimensões, mesmo que com um crescimento distribuído de forma homogênea entre as atividades econômicas e as sociedades, ainda assim, de tempos em tempos, precisa rever suas práticas econômicas, promovendo algumas reformas ou criando novas estruturas e extinguindo outras. Ou seja, “[...] ao longo do tempo, o próprio sucesso faz com que as instituições percam sua funcionalidade, sendo transformadas ou dando lugar a outras instituições e a outras formas de organizar a atividade econômica” (SATO, 2012).

Os países membros da OMC acordaram um mandato negociado nos moldes das rodadas anteriores à criação da organização, não levando em conta os desafios impostos pelas novas dinâmicas do comércio internacional. "Dessa forma, a agenda de Doha e seu mandato revelaram-se alheios a essas mudanças e ajudam a explicar por que Doha já nasceu obsoleta" (CESAR; SATO, 2012, p. 175).

Ao longo dos dez anos de negociação da rodada, os impactos da globalização da produção tornaram-se ainda mais evidentes, mas não foram efetivamente incorporados em sua agenda. Essa

${ }^{3}$ Em uma rodada de negociações, " [...] os diversos órgãos da OMC se reúnem regularmente para monitorar a implementação dos acordos em vigor, bem como a execução da política comercial dos países membros, negociar a acessão de novos membros e acompanhar as atividades relacionadas ao processo de solução de controvérsias" (MINISTÉRIO DAS RELAÇÕES EXTERIORES, 2011).

\section{[...] É difícil imaginar que no meio de uma fase de crescimento, ou mais ainda, na fase em que um período de crescimento está} produzindo seus melhores resultados, teses e propostas com vistas a mudanças nos regimes sejam acolhidas. Foi exatamente 0 que aconteceu com a Rodada Doha. Os dados mostram que nos anos da década e meia que antecederam a Rodada Doha a economia mundial cresceu de forma consistente e o comércio, por sua vez, também manteve taxas de desempenho acompanhando a trajetória crescente do PIB mundial [...]; antes mesmo de ser lançada, a Rodada Doha já nascia, em grande medida, carente de um propósito. É difícil pensar que num ambiente onde o crescimento estava se espalhando pela economia mundial pudesse haver forças econômicas preocupadas em promover mudanças no regime de comércio, mesmo que num país ou noutro esse crescimento não se verificasse (SAT0, 2012). 
desconexão entre as novas realidades da economia internacional e o espírito negociador da rodada seria umas das grandes causas de seu insucesso (CESAR; SATO, 2012, p.175).

É importante notar que, nos principais documentos referentes às negociações da Rodada Doha da OMC, pouca ou nenhuma referência foi encontrada sobre as novas dinâmicas do comércio internacional e a necessidade de adaptação ou evolução das regras do sistema multilateral de comércio em resposta à realidade (CESAR; SATO, 2012, p. 181).

Prazeres (2008, p. 492) acredita que quanto maior for a defasagem entre as negociações multilaterais e a realidade do comércio internacional, menos importância terá a OMC no contexto econômico-internacional, pois, com isso, "[...] mais se amplia a defasagem entre a realidade e o poder de a organização influenciá-la”.

Num cenário em que o regime multilateral não evolui e que os blocos se proliferam e se aperfeiçoam, é natural que a OMC perca capacidade de regular e monitorar os fluxos comerciais, e que vá se desconectando da realidade econômico-comercial da atualidade. $\mathrm{E}$, nessa linha, quanto maior a defasagem entre a OMC e os fluxos da realidade, menor é sua relevância (PRAZERES, 2008, p. 438).

Cada membro da OMC possui uma realidade diferente, demandando regras diferenciadas. Como esta é uma instituição que estabelece regras gerais, comuns a todos os países, a relação custo/benefício se dá por formas diferentes para cada Estado, “[...] o que pode determinar comportamentos diferenciados em relação ao cumprimento das regras negociadas” (CAMPOS, 2008, p. 132).

Além disso, a tendência da OMC por absorver os conflitos multidimensionais nos quais seus membros estão envolvidos leva a instituição a enfrentar problemas crescentes de legitimidade, que são cada vez mais graves, sem que esta tenha meios para lidar com tais complicações. Esta situação acaba por enfraquecer o seu sistema de negociações multilaterais (CRUZ, 2005, p.104).

\section{A RODADA DOHA E SEUS ENTRAVES}

Como já foi posto antes, a Rodada Doha era a esperança de que o multilateralismo se fortaleceria. No entanto, quando seguidos impasses tornaram-se realidade 
nas negociações comerciais, percebeu-se que seria muito difícil alcançar os objetivos propostos em Doha e, consequentemente, seria difícil potencializar o sistema multilateral de comércio.

Desde 2001 diversos autores tentam achar os possíveis motivos e explicações para as paralisações nas negociações multilaterais no âmbito da OMC. Pode-se elencar vários desses motivos e perceber que, em conjunto, eles demonstram o quanto essas negociações são complexas. Alguns deles serão discutidos em seguida para que então se possa refletir sobre a atual posição do multilateralismo dentro das negociações comerciais internacionais.

\subsection{AGENDA DE DOHA}

A agenda de negociações comerciais de Doha adquiriu uma crescente complexidade, dado o surgimento de um maior número de temas a serem discutidos, cada qual com particularidades técnicas próprias. Juntamente com isso, faz-se necessário considerar que a OMC possui um número cada vez maior de membros, os quais “[...] se encontram em etapas diferentes de desenvolvimento econômico, defendem interesses comerciais distintos e exibem pesos desiguais na economia globalizada" (AZEVÊDO, 2009, p. 2).

No passado, a formação de consensos dependia em grande parte de um entendimento entre alguns países desenvolvidos. Hoje, além da participação ativa e significativa das grandes economias emergentes (Brasil, China, Índia) no processo negociador, os pleitos dos países menores que lograram articular-se coletivamente para promover seus interesses [...] não podem deixar de ser considerados. Ademais, à medida que as modalidades negociadoras são discutidas em maior detalhe, vêm à tona problemas concretos e sensibilidades agudas que antes passavam despercebidos no contexto de entendimentos de caráter geral (AZEVÊDO, 2009, p. 2).

“[...] O novo programa de trabalho acentuou os desequilíbrios do regime comercial, em lugar de buscar endereçá-los, principalmente ao priorizar os temas de interesse dos países desenvolvidos em relação aos interesses da maior parte dos membros da OMC" (WEBER, 2009, p. 280).

A ambiguidade existente entre a paralização da rodada e os impasses recorrentes nas negociações ocorre devido à forma como a Declaração Ministerial 
de Doha determinou os temas para discussão e negociações posteriores, pois "[...] permanece a incerteza acerca do conteúdo exato que deveria conformar um resultado final” (WEBER, 2009, p. 283).

Os resultados obtidos na rodada caminham em direções opostas e contribuem pouco para o encerramento a curto prazo das negociações. "São diversos os atores, os temas e os interesses reunidos na Rodada Doha. Cada campo de negociação tem dinâmicas próprias e a complexidade aumenta diante da forte interligação entre tudo o que está sendo debatido" (RIBEIRO, 2007, p. 24).

Além disso, a agenda da Rodada Doha colocou enfoque nas questões agrícolas, as quais, na realidade, referem-se a menos de $10 \%$ dos valores transacionados no comércio internacional (SATO, 2012).

É importante notar que esse declínio refere-se apenas à participação relativa e não a valores e volumes absolutos, que foram sempre crescentes, significando que as nações exportadoras, tanto quanto as importadoras, não tinham muito do que se queixar com o desempenho do comércio (SATO, 2012).

Delgado (2007) salienta que os próprios termos em que a questão das negociações é colocada - ao vincular o desenvolvimento dos países em desenvolvimento com liberalização comercial agrícola - constitui-se num labirinto de difícil saída. Segundo Campos “ os produtos agrícolas apresentamse como os responsáveis pelo não encerramento da Rodada Doha, exigindo ainda negociações importantes dentro do grupo de Estados desenvolvidos" (CAMPOS, 2008, p. 133).

Há uma dificuldade em se avançar consistentemente nas negociações lançadas pela Conferência Ministerial de Doha se “[...] não ocorrer uma revisão substantiva das regras aplicáveis à agricultura (e nos três pilares que conferem sustentação ao acordo: subsídios à exportação, apoio doméstico e acesso a mercados)" (PRAZERES, 2008, p. 73).

A Rodada Doha fracassou porque a comunidade de Estados não chegou a um consenso sobre as novas regras para a liberalização do comércio internacional. De um lado, os países europeus e os EUA queriam que os emergentes reduzissem a taxa de importação dos produtos industrializados e de serviços; de outro, os países em desenvolvimento exigiam a forte redução dos subsídios agrícolas, para que tivessem maior acesso aos mercados dos países industrializados. "O grande desafio da Rodada Doha era chegar a um consenso para estabelecer regras que favoreçam tanto os países em desenvolvimento quanto os países desenvolvidos" (LOPES, 2009). 


\subsection{PROTECIONISMO}

O aumento do protecionismo por parte de alguns países desenvolvidos também pode ser apontado como fator de impasse às negociações multilaterais. "Apesar de a liberdade comercial ter obtido, ao longo dos anos, feitos consideráveis com redução de tarifas, importações e exportações contribuindo efetivamente para que os países se recuperassem da devastação da II Guerra Mundial [...]”, a abertura de oportunidades para as nações menos desenvolvidas não seguiu a mesma direção (WOJCIECHWSKI, 2002, p. 16).

Apesar do discurso político do livre comércio, “[...] o que se tem constatado, no período de vigência do GATT à OMC, é a prática do crescente protecionismo" (MEDEIROS, 2002, p. 13).

A existência de barreiras naturais à entrada; a ajuda governamental; normas técnicas, ambientais e outras; concessões públicas, principalmente em setores estratégicos; e propriedade industrial; configuram o panorama das barreiras que engessam a ideia utópica do livre comércio. [...] Falar em livre comércio constitui uma falácia, tendo em vista que as grandes potências como Estados Unidos, União Europeia e o Japão, subsidiam diversos setores da produção doméstica, inclusive a agricultura (MEDEIROS, 2002, p. 13).

Mesmo tendo sido feitas declarações pelos diversos líderes mundiais em prol do multilateralismo, tanto em âmbito regional quanto global, prevalecem instabilidades no sistema comercial. Dada a intensa ligação doméstica que o tema envolve, os compromissos assumidos demandam ações políticas que nem sempre são preferenciais para os países envolvidos, fato que "[...] aprofunda tendências de protecionismo e unilateralismo no setor comercial (e, no geral, no setor econômico), com perspectiva de curto prazo" (PECEQUILO, 2012, p. $355)$.

Com isso, a opção é pelo estabelecimento de projetos mais ligados a grupos de interesse internos, de tratados bilaterais de baixo custo para o parceiro dominante, o que leva ao cenário denominado de spaghetti bowl, com a sobreposição de todas estas iniciativas, muitas vezes em contradição com as regras multilaterais da OMC (PECEQUILO, 2012, p. 355). 


\subsection{CONFERÊNCIAS MINISTERIAIS}

Pode-se observar que, conforme aconteciam as conferências ministeriais da Rodada Doha, foram surgindo cada vez mais divergências nas negociações comerciais. Isso levou diversos autores a afirmar que a rodada deveria ser encerrada mesmo sem ter atingido algum de seus objetivos.

No período de 2001 a 2003, entre o lançamento da Rodada Doha e a Conferência Ministerial de Cancun, “[...] o aprofundamento [das] tendências ao Sul, associadas às resistências do Norte em mudar suas posições levou a uma estagnação relativa do quadro negociador" (PECEQUILO, 2012, p. 353).

Com a formação de coalizões em Cancun, houve um colapso nas negociações comerciais. Este colapso levantou dúvidas quanto à governança do processo decisório da OMC, “[...] a despeito dos avanços implementados desde a última ministerial para melhorar a transparência do processo de consultas da OMC”, pois os custos de informação permaneceram altos para muitos membros que possuíam apenas uma fraca presença em Genebra (WEBER, 2009, p. 300).

Em dezembro de 2005, deu-se a sexta conferência ministerial da OMC, em Hong Kong. Seu resultado consistiu-se em poucas concessões para os países em desenvolvimento em troca de substanciais concessões ao mundo desenvolvido. O processo obtido em Hong Kong foi muito modesto; seguiu o ritmo do impasse anterior ao encontro, com a agricultura representando o ponto central das divergências (WEBER, 2009, p. 344).

Houve um recomeço formal das negociações de Doha com o Fórum Econômico Mundial de Davos, em 2007, no qual se discutiu amplamente sobre a recessão dos Estados Unidos e suas consequências - que causavam uma desaceleração econômica mundial, gerando crescimento do protecionismo comercial. Posteriormente ao encerramento deste, os membros da OMC dirigiram-se a Genebra, retomando os debates da rodada (WEBER, 2009, p. 372).

Apesar do esforço em superar o impasse das negociações buscando incluir mais países nas simulações de resultados da OMC, a ausência de vontade política dos principais atores não permitiu que as grandes divergências que sobreviveram a Hong Kong fossem resolvidas em Genebra. “[...] Em contrário, nesses encontros, tanto UE quanto os EUA passaram a enrijecer suas posições negociadoras" (WEBER, 2009, p. 348). 


\subsection{CRISE DE 2007-2008}

As crises causam uma tendência global em favor do nacionalismo econômico e dificultam o sistema multilateral de comércio (PRAZERES, 2008, p. 64). A crise desencadeada no mercado hipotecário estadunidense em 2007 - a qual não retrocedeu nos anos seguintes - estendeu-se não apenas geograficamente, mas alcançou outras áreas da economia, gerando grandes efeitos, principalmente, na produção e no comércio (MENEZES, 2009, p. 12).

Em 2009, os riscos relacionados ao aumento do protecionismo, dados os efeitos da crise, ainda eram iminentes e o aprofundamento desta poderia levar os países a tomarem medidas neste sentido. Retrocessos protecionistas agravariam a já debilitada situação da economia mundial naquele momento (MENEZES, 2009, p. 13).

Com a crise, as negociações deram-se sob circunstâncias bastante complexas:

Do ponto de vista econômico, o agravamento da crise financeira internacional, com a retração a atividade produtiva e o aumento do desemprego, gera pressões protecionistas e inspira demandas pela concessão de subsídios e adoção de outros mecanismos de apoio, em particular nos setores financeiro, agrícola, siderúrgico e automobilístico. Do ponto de vista político, o processo de revisão em curso da política comercial norte americana, corolário da assunção de uma nova administração nos EUA, aliado à circunstância de que destacados membros da OMC encontram-se em pleno ciclo eleitoral, agrega dificuldade ao processo de tomada de decisões (AZEVÊDO, 2009, p. 2).

Para Neves (2013), uma justificativa para o travamento das negociações comerciais reside "[...] no interstício entre a crise internacional e o grande número de países com perspectivas díspares que são membros da organização atualmente".

Pode-se dizer que em tempos de dificuldade no ajuste das contas nacionais, a vontade política para realizar acordos de liberalização do comércio são bastante diminuídas, mesmo havendo certo consenso de que as barreiras são prejudiciais aos fluxos comerciais como um todo. Porém, em um sistema no qual os ganhos são difusos e as perdas concentradas, a posição de determinados países 
dentro da organização acaba criando empecilhos naturais para o desenvolvimento das negociações multilaterais. Além disso, a própria estrutura das negociações da OMC é um grande entrave para a evolução nas bases normativas que estão inseridas nesse contexto de dificuldades econômicas. Em geral, um dos princípios fundamentais das negociações pode ser definido pela expressão inglesa single undertaking, ou seja, significa dizer que partes do acordo pertencem a um bloco que não pode ser dividido em vários eixos (NEVES, 2013).

\subsection{REGIONALISMO}

Segundo o princípio da cláusula da nação mais favorecida, uma vantagem comercial concedida a qualquer membro da OMC deve imediatamente ser estendida a todos os outros membros da organização. Este princípio evita a discriminação em relação a produtos oriundos de países diferentes, promovendo uma equalização nas vantagens do comércio internacional e, por consequência, facilitando o acesso igualitário a mercados. "[...] A cláusula da nação mais favorecida contribui de maneira substancial para o caráter multilateral do regime de comércio articulado pela OMC" (PRAZERES, 2008, p. 95).

Considerando o princípio acima, pode-se perceber que a própria essência de um acordo regional que conceda preferências tarifárias "[...] contraria a lógica da não discriminação, uma vez que é de sua natureza a concessão de vantagens a um grupo limitado de países, ou seja, a discriminação com fundamento na origem do produto" (PRAZERES, 2008, p. 93).

$\mathrm{O}$ que se tem observado nos últimos anos foi a tendência à procura, por parte dos países, de soluções a níveis bilaterais e regionais, “[...] com o intuito de criar maneiras mais eficazes de dinamizar o comércio internacional em tempos de crise" (NEVES, 2013).

Um dos problemas cruciais da OMC é a proliferação do regionalismo, o qual se tornou a principal causa que dificulta o sistema multilateral de comércio. Além disso, os países se intimidam em denunciar os abusos dos acordos regionais dos demais países, “[...] criando a síndrome do telhado de vidro, isto é, nenhum membro do regime quer denunciar os outros com medo de ser denunciado também". Os países não reconhecem a importância de um mecanismo multilateral para a consecução de temas que se iniciam na economia e que se espalham para a política, a segurança, o bem estar social 
etc. "O protecionismo gerado pelos grupos regionais neste contexto pode gerar desigualdades [...]” (ROMERO, 2011, p. 24).

O fato de uma real explosão de acordos regionais tem desviado o debate [sobre os acordos multilaterais] e os países não têm se demonstrado disposição de mudar a atual situação. [...] Mais e mais acordos de preferências tarifárias são acordados, pois os países não querem esperar a evolução no plano multilateral que se mostra extremamente vagarosa. [...] O fato irrecusável é que a atual rodada se vê estagnada e como fruto de tal estagnação os países continuam a negociar bilateralmente (ROMERO, 2011, p. 70-71).

Em geral, “[...] quando analisada à luz do sistema multilateral de comércio, a formação de blocos regionais é percebida como um movimento de ruptura, uma força de natureza centrífuga diante do empuxo provocado pelo fenômeno do multilateralismo" (PRAZERES, 2008, p. 104).

Se o regime multilateral de comércio reúne seus membros a partir de princípios gerais de conduta, e se a cláusula da nação mais favorecida é um de seus princípios centrais, “[...] parece que, de fato, há um risco para a credibilidade do regime, se praticamente todos os seus membros, em menor ou maior grau, se desviam das regras adotadas" (PRAZERES, 2008, p. 112).

Ao avaliar a configuração dos acordos comerciais nos dias de hoje, percebe-se com facilidade que, deliberadamente ou não, os Estados estabeleceram um sistema de dois planos: constituíram uma camada multilateral que vincula praticamente todos, ao mesmo tempo em que conformaram uma série de acordos paralelos que, se têm abrangência limitada pelo ponto de vista dos participantes, são mais ambiciosos na perspectiva da liberalização comercial do que as regras do regime multilateral (PRAZERES, 2008, p. 119).

Os membros da OMC buscam promover por meio do regionalismo interesses que não têm sido bem atendidos no âmbito multilateral. No entanto, estes motivos não são suficientes para que os participantes dos blocos regionais percam interesse por um regime comercial de abrangência ampla.

Argumenta-se, assim, que há incentivos importantes para o engajamento regional e há vantagens distintas na via multilateral. 
Ao mesmo tempo, o regime multilateral não é capaz de definir constrangimentos eficazes para que seus membros deixem de acionar a via regional (PRAZERES, 2008, p. 381).

Além disso, há uma lógica que aglutina os interesses que podem ser melhor ou mais facilmente promovidos no âmbito regional, em relação à esfera multilateral. "A esse fator se soma a manutenção da prática do consenso no processo decisório da organização e o resultado é a dificuldade brutal para a tomada de decisão e para o avanço das negociações comerciais”. Países que têm interesse em obter resultados com maior agilidade e liberalizar com maior ambição são estimulados a participar de acordos regionais (PRAZERES, 2008, p. 386-387).

Argumentos como o aumento de oportunidades para empresas locais, o estímulo à concorrência, o incentivo à eficiência econômica - em geral associados ao livre comércio - são empregados em defesa do regionalismo à medida que os avanços das negociações multilaterais se apresentam difíceis e às vezes pouco prováveis. Além da velocidade das negociações, destaca-se que os blocos tendem a atingir resultados mais ambiciosos que os obtidos na esfera multilateral (PRAZERES, 2008, p. 387).

Mesmo que os compromissos assumidos no plano regional não contrariem os compromissos assumidos na OMC, eles consolidam regimes distintos entre si para o tratamento dos mesmo temas, “[...] o que pode dificultar o processo de convergência de disciplinas no âmbito multilateral”. Além disso, deve-se considerar a hipótese de que os países resistam à abertura multilateral por já terem feito concessões no âmbito regional (PRAZERES, 2008, p. 432).

A política de negociação de acordos regionais pode estar roubando energia, tempo e atenção dos membros da OMC, prejudicando as negociações multilaterais. Com recursos escassos, os Estados tendem a concentrar esforços nas negociações regionais, nas quais os resultados podem ser obtidos a curto prazo e o risco de impasse é menor (PRAZERES, 2008, p. 442).

Com isso, durante a Rodada Doha, não tem sido possível estabelecer um vínculo entre o regionalismo e uma contribuição positiva para as negociações comerciais multilaterais. Como agravante, “[...] a mudança de estratégia comercial norte americana pode, de alguma forma, prejudicar a suposta engrenagem entre as ações no plano regional e multilateral" (PRAZERES, 2008, p. 466). 
Quanto mais tempo o regime multilateral levar para reduzir os prejuízos e antecipar e/ou promover os benefícios dos arranjos regionais, maior será "[...] a defasagem entre as disciplinas multilaterais e os fluxos da realidade e, consequentemente, menor será a importância da OMC para o comércio mundial" (PRAZERES, 2008, p. 471).

Além das dificuldades decorrentes da falta de entendimento político a respeito do regionalismo, a OMC precisa lidar com dificuldades institucionais relacionadas ao seu próprio funcionamento; principalmente as relacionadas ao grande número de seus membros e a heterogeneidade entre eles, e a praxe consolidada das decisões apenas com base no consenso. "A paralisia decisória da OMC é especialmente prejudicial para a resposta que a organização possa oferecer ao fenômeno do regionalismo" (PRAZERES, 2008, p. 474- 475).

\begin{abstract}
[...] Manter as normas como estão implica um custo para o regime multilateral. Se o regionalismo avança e o multilateralismo não aperfeiçoa seus instrumentos para lidar com o tema, maior é a incapacidade de a OMC exercer alguma influência sobre o comportamento de seus membros (PRAZERES, 2008, p. 477).
\end{abstract}

Somente uma compreensão mais detalhada do papel do regionalismo em um regime multilateral de comércio pode permitir que a $\mathrm{OMC}$ potencialize os benefícios dos acordos regionais e minimize seus efeitos negativos sobre o multilateralismo comercial (PRAZERES, 2008, p. 481).

\title{
5.6 ELEIÇÃO DE UM NOVO DIRETOR-GERAL DA OMC
}

Quanto à eleição de Roberto Azevêdo para diretor geral da OMC, Domingues (2013) afirma que esta “[...] confirmou a existência de uma transformação em curso na geopolítica do comércio internacional, que tem suas raízes na Rodada Doha”. Thorstensen (2013, p. 4) acredita que a escolha de um brasileiro para o cargo de diretor geral da OMC tem vários significados. Para a autora, esta escolha representa uma "[...] quebra do modelo anterior, em que os Estados Unidos e a União Europeia formavam o núcleo do poder, impondo os nomes da direção e os temas das discussões".

A partir de então, os países emergentes, liderados pelos BRICs, conseguiram formar “[...] uma coalizão que exigiu um novo estilo de governança”. Roberto Azevêdo representa o fortalecimento do multilateralismo e um impulso para a retomada das negociações da Rodada Doha, visto que nela encontram-se interesses de muitos países em desenvolvimento (THORSTENSEN, 2013, p. 4). 
Discordando deste ponto de vista, Miyazaki (2014) acredita que a eleição de um diretor geral advindo de um país em desenvolvimento não leva à facilitação do final da rodada: “[...] de qualquer forma, o diretor geral foi eleito e não é a primeira vez que na OMC existe um diretor geral oriundo de um país em desenvolvimento. Já houve um tailandês neste cargo" (MIYAZAKI, 2014, informação verbal ${ }^{4}$ ).

O fato de o diretor geral ser de um país em desenvolvimento não prejudica as negociações nem ajuda. Se agora os países em desenvolvimento têm um brasileiro como diretor geral, era de se esperar que isso pudesse ajudar. Mas, na verdade, o que acontece é que ele como diretor geral não pode tomar partido de jeito nenhum. Segundo, isso também não é novidade, porque antes dele já houve um diretor geral da Tailândia. No fim das contas, o poder real não recai tanto sobre o diretor geral, mas apenas sobre os membros da OMC. O diretor geral deve ser neutro (SÁ PORTO, 2014, informação verbal ${ }^{5}$ ).

\subsection{COALIZÕES E FORMAÇÃO DE CONSENSOS}

As coalizões dentro na OMC desempenharam e continuam a desempenhar um papel importante no processo negociador. É importante o fato de que elas atuem como mecanismos ndamento deste processo negociador. "Nesse sentido, as coalizões preenchem papel essencial no que concerne à transparência, inclusão e intercâmbio de informações entre os seus membros” (DAMICO, 2011, p. 3).

de consulta e coordenação, bem como troca de opiniões regulares a respeito do a

O processo decisório baseado no consenso se apresenta como um dilema cada vez maior para a OMC, consistindo em uma força e uma fraqueza da organização, pois há uma grande dificuldade nas negociações envolvendo tantos países membros. "Com isso, a formação de coalizões poderia facilitar a construção do consenso, aumentando a representatividade e legitimidade da organização". No entanto, haveria um aumento de representatividade ao custo de aumentar também a inflexibilidade política e, portanto, os riscos de falência das negociações (WEBER, 2009, p. 301).

A impossibilidade de se atingir um acordo na Rodada Doha está ligada - além do processo decisório ineficiente - a um movimento de transição das lideranças do comércio internacional, que gradualmente estariam se refletindo

${ }^{4}$ Informação verbal obtida através de entrevista com Silvio Yoshiro Mizuguchi Miyazaki, em 1 de abril de 2014.

${ }^{5}$ Informação verbal obtida através de entrevista com Paulo Costacurta de Sá Porto, em 3 de abril de 2014. 
nas negociações e barganhas informais internas ao processo de construção do consenso (CESAR, 2013).

\begin{abstract}
Um maior número de coalizões e o crescente protagonismo de países emergentes reconhecidamente desafiaram a liderança do antigo 'Quad' (Estados Unidos, Japão, Canadá e União Europeia) na Rodada Doha, tornando qualquer decisão consensual mais complexa e demandando esforços políticos que muitas vezes Estados Unidos e União Europeia não se mostraram dispostos a realizar para mover as negociações (CESAR, 2013).
\end{abstract}

Em meio ao impasse nas negociações da Rodada Doha, existe o receio de que a OMC perca relevância. Há críticas em relação ao arcabouço do sistema multilateral de comércio, dado que este é baseado na busca pelo consenso, fato que leva a um processo de negociação exageradamente ineficiente e politizado. "Caso a OMC queira se adaptar às realidades e às demandas do sistema comercial moderno, é necessária maior flexibilidade e eficiência - ou mesmo a aceitação da existência de 'geometrias variáveis' quanto aos direitos e obrigações dos membros” (VICKERS, 2013).

Para Vickers (2013), uma saída para este problema poderia ser o estabelecimento de acordos plurilaterais ${ }^{6}$, pois:

Teoricamente, tais acordos permitiriam o avanço de uma agenda comercial mais dinâmica, reduziriam a multiplicidade de iniciativas sob a forma de acordos regionais, promoveriam uma diferenciação mais eficiente em termos de direitos e obrigações em um conjunto de países bastante heterogêneo e garantiriam mecanismos para promover maior eficiência às negociações da OMC (VICKERS, 2013)

No entanto, por outro lado, a via plurilateral talvez seja uma resposta limitada para os desafios enfrentados pela OMC na atualidade. A governança do sistema multilateral de comércio deve lidar com três demandas fundamentais: maior eficiência, inclusão e legitimidade. Com isso, uma estratégia focada apenas na busca por acordos plurilaterais mais eficientes possui claras limitações (VICKERS, 2013). 


\section{A CONFERÊNCIA MINISTERIAL DE BALI}

A revista The Economist (2013) reconhece que, durante os últimos doze anos, muitas vezes os esforços para alcançar um acordo na Rodada Doha foram taxados como destinados ao fracasso. Mas todas as notícias sobre o fim da rodada tornaram-se extremamente exageradas quando, no início de dezembro de 2013, em Bali, foi realizado um acordo (THE ECONOMIST, 2013).

Na manhã do dia 6 de dezembro de 2013, em Bali, os ministros do comércio dos países membros da OMC concluíram formalmente seu primeiro acordo em quase duas décadas (PONTES, 2013).

O acordo final inclui uma declaração ministerial de três páginas, a qual reconhece a adesão do Iêmen e adota decisões em dez textos sobre os três pilares do pacote de Bali: facilitação do comércio, questões agrícolas e disposições específicas acerca do desenvolvimento. De acordo com analistas, o pacote de Bali pode dar um impulso substancial no comércio mundial, com algumas estimativas indicando um possível aumento do Produto Interno Bruto (PIB) global em US\$ 1 trilhão (PONTES, 2013).

$\mathrm{Na}$ verdade, o acordo é bastante modesto, apenas englobando a facilitação do comércio, e não a ampla liberalização objetivada em Doha. Entretanto, é o primeiro acordo global feito desde a existência da OMC (THE ECONOMIST, 2013). No entanto, apesar de a facilitação comercial ter sido uma conquista significativa, o acordo não convenceu os céticos de que o progresso do multilateralismo possa levar a reformas ambiciosas (THE ECONOMIST, 2013).

Com o encerramento da Conferência de Bali, os membros decidiram "revisitar" as outras negociações comerciais de Doha e, com isso, concordaram em preparar, durante todo o ano de 2014, um programa de trabalho melhor definido sobre como tratar dos demais temas envolvidos na rodada que ainda não obtiveram um consenso (PONTES, 2013).

As principais áreas de embate nas negociações têm girado em torno do acesso ao mercado agrícola e não agrícola, e da necessidade de reformar políticas de apoio à agricultura doméstica. A área de serviços, que compõe a terceira parte da chamada 'tríade do acesso a mercado', também teve pouco ou nenhum avanço em anos [...] (PONTES, 2013). 
Sendo assim, Os países membros da OMC tratarão, em 2014, de dois grandes desafios: a implementação do pacote de Bali e o desenvolvimento de um programa de trabalho que seja capaz de encaminhar os outros assuntos pendentes da agenda da Rodada Doha (PONTES, 2014).

Miyazaki (2014) defende que Bali teve um ponto positivo: foi, de forma simbólica, uma espécie de salvação da Rodada Doha. No entanto, o autor defende que "[...] os países da OMC deveriam encerrar presente rodada de negociações e começar outra, incluindo na pauta os acordos de preferências comerciais, os quais estão cada vez mais dinâmicos no mundo" (MIYAZAKI, 2014, informação verbal ${ }^{7}$ ).

Contrariamente, Sá Porto (2014, informação verbal ${ }^{8}$ ) defende que ainda existe a possibilidade de se obter sucesso na Rodada Doha, pois há vários temas sendo negociados.

O tema menos polêmico de todos, facilitação de comércio, teve a possibilidade de alcançar um acordo em Bali. O consenso dificulta os acordos, mas em relação a esse tema foi possível chegar a ele. Em relação aos outros temas, alguns bastante polêmicos, como acesso a mercados, serviços e investimentos, é mais difícil se chegar a um acordo. Por outro lado, não se deveria desistir, até porque se pode convergir progressivamente para a possibilidade de que haja mais negociações (SÁ PORTO, 2014, informação verbal ${ }^{9}$ ).

\section{CONCLUSÃO}

A partir de todos esses pontos indicados, pode-se observar que as negociações multilaterais têm encontrado diversos obstáculos e divergências - causando paralisações nas negociações, as quais levam, geralmente, muito tempo para se resolverem. Estes impasses acarretam danos ao sistema multilateral de comércio, pois diminuem sua eficiência e reduzem sua confiabilidade e eficácia.

Em primeiro lugar, observa-se que mudanças na forma como o comércio internacional é realizado, derivadas principalmente da dissipação do processo de globalização, impactaram na eficiência do multilateralismo, visto que a necessidade de reforma do último tornou-se latente, além do surgimento de novos atores e novos canais de negociação. E ainda, há uma divergência entre o acelerado ciclo de produção e inovação dos mercados globais e o lento ciclo de negociações multilaterais de comércio. 
As cadeias globais de valor, estruturadas pelas transnacionais, veem as regras tradicionais da $\mathrm{OMC}$ - tarifas, antidumping e regras de origem - como fontes de custos e barreiras comerciais. Desta forma, acordos preferenciais de comércio, tanto bilaterais quanto regionais, tendem a se difundir com grande frequência, criando um sistema paralelo de regras de comércio externo à OMC.

Os países acordaram uma agenda para a Rodada Doha moldada de forma semelhante às rodadas anteriores à criação da organização, sendo assim, os desafios impostos pelas novas dinâmicas do comércio internacional não foram incorporados a ela. Com isso, alguns autores acreditam que exista uma desconexão entre a nova realidade do comércio mundial e as negociações da rodada, permanecendo o descolamento entre o mundo real, a agenda das negociações e as disputas de poder. Desta forma, cada vez mais se amplia a defasagem entre a realidade e o poder da OMC de influenciá-la.

A agenda de Doha adquiriu grande complexidade por ter um número extenso de temas a serem discutidos, cada um com suas particularidades e complicações, e por envolver um número cada vez maior de países, os quais se encontram em níveis diferentes de desenvolvimento econômico, defendem interesses comerciais diferentes e têm influências desiguais no comércio internacional.

Com a crise financeira global, iniciada em 2007 nos Estados Unidos, as circunstâncias para as negociações do sistema multilateral tornaram-se bastante complexas, gerando pressões protecionistas e inspirando concessões contrárias aos objetivos dessas negociações. Esse aumento do protecionismo e a ascensão de acordos preferenciais acabaram prejudicando a já debilitada rodada de negociações comerciais. A proliferação do regionalismo tornou-se uma das principais preocupações da OMC, dado que os acordos regionais dificultam o sistema multilateral de comércio e que os países se intimidam em denunciar os abusos regionais praticados por outros países. Além disso, o protecionismo ocasionado pelos grupos regionais aumenta cada vez mais a desigualdade.

O multilateralismo promove uma liberalização comercial mais eficiente em termos econômicos, permite a discussão de alguns temas de caráter sistêmico que não podem ser discutidos em outras formas de negociações comerciais, propicia segurança jurídico-institucional e estabilidade a seus membros e garante o compartilhamento de regimes equitativos, racionalizando a multiplicação de obrigações. Entretanto, com a formação de blocos regionais, aspectos cruciais ao bom funcionamento do multilateralismo, como a transparência e a previsibilidade, são desgastados.

A teoria da liberalização competitiva defende que a busca pela liberalização comercial por parte do regionalismo e do multilateralismo promove uma 
competição entre ambos, favorecendo o segundo. Em concordância, a teoria do dominó sustenta que a formação de um bloco regional leva à formação de outros blocos, cada vez mais envolvendo um número maior países, contribuindo, assim, para a prosperidade do sistema multilateral de comércio. Todavia, questiona-se a aplicabilidade dessas teorias atualmente, pois o regionalismo está amplamente disseminado. Desta forma, ele tende a promover mais regionalismo do que mais multilateralismo.

No que concerne à eleição do brasileiro Roberto Azevêdo para diretor geral da OMC, as opiniões são divididas. Alguns autores afirmam que ela é a confirmação de uma transformação em andamento do comércio internacional, demonstrando a crescente importância dos países em desenvolvimento na esfera de negociações multilaterais, uma mudança na distribuição de poder entre os Estados. Acreditam que a eleição de Azevêdo

leve a uma maior dinamização das negociações e melhore a situação dos países em desenvolvimento nessas negociações.

Contrariamente, outros autores creem que a eleição de um diretor geral oriundo de um país em desenvolvimento não leva a facilitações que possam finalizar Doha. Além disso, argumentam que esse não é um fato isolado, pois já houve um diretor geral tailandês. Complementarmente, observam que o poder de decisão nas negociações recai totalmente sobre os países membros da OMC, e não sobre Azevêdo. Já a formação de coalizões pode influenciar na tomada de decisões dentro da instituição multilateral, contribuindo para a formação de consensos. Desta forma, as coalizões respaldam uma conduta importante no processo negociador.

$\mathrm{O}$ processo decisório vigente na $\mathrm{OMC}$ baseado no consenso representa ao mesmo tempo uma força e uma fraqueza da organização, dificultando as negociações. Nesse sentido, as coalizões podem facilitar o alcance do consenso, elevando a legitimidade e representatividade da instituição. No entanto, correse o risco de que a inflexibilidade política aumente também, podendo ocasionar uma falência nas negociações. Portanto, contrabalanceando os efeitos, as coalizões podem gerar paralisações e atrasos nas negociações multilaterais.

Alguns autores acreditam que, se os Estados Unidos e a União Europeia assumissem um papel de liderança, haveria maiores chances de se resolverem os impasses que persistem na Rodada Doha. Entretanto, a emergência de outros atores de importância no âmbito das negociações dificulta a possibilidade disso acontecer. Desta forma, parece que cada vez mais o consenso distancia-se de algo a ser alcançado, pelo menos a curto prazo.

Com isso, diversos autores criticam a prática do consenso por parte da $\mathrm{OMC}$, visto que ela muitas vezes ocasiona riscos potenciais de paralisia nas 
negociações comerciais multilaterais. Sendo assim, a organização pode perder sua relevância no contexto internacional. Alguns autores julgam a busca pelo consenso como um processo ineficiente e politizado.

Uma saída para esta situação pode ser dada pelo estabelecimento de acordos plurilaterais, pois eles poderiam garantir negociações mais dinâmicas e eficientes. No entanto, eles poderiam causar problemas de legitimidade e inclusão; ou seja, atenderiam apenas uma das três demandas fundamentais com as quais o sistema multilateral deve lidar.

Acredita-se que, se não forem atingidos consensos quanto aos temas da agenda de Doha e a rodada finalizar-se fracassada, a credibilidade do sistema multilateral de comércio será fortemente questionada. A OMC corre sérios riscos de perder importância no contexto econômico internacional. Para que isso não ocorra, é preciso que os países, pelo menos, diminuam seu protecionismo e percebam o quão importante é o sistema multilateral de comércio para o mundo. Os Estados precisam compreender que toda a comunidade internacional será prejudicada se Doha falhar.

Mas um passo foi dado à frente, em dezembro de 2013, na Conferência Ministerial de Bali. Nesta ocasião foi feito um acordo de facilitação de comércio entre os países membros da OMC. Espera-se que o pacote de Bali dê um substancial impulso no comércio mundial a partir de sua implementação.

Analistas mais pessimistas defendem que o acordo é modesto por englobar apenas a facilitação de comércio e não a ampla liberalização objetivada por Doha. No entanto, este foi o primeiro acordo mundial feito no âmbito da OMC. Embora ainda existam muitos temas a serem tratados na rodada, é melhor ter o pacote de Bali a não ter nenhum. Além disso, os países fizeram a promessa de se dedicarem, durante todo o ano de 2014, à implementação do pacote e ao planejamento de um programa que encaminhe os temas ainda pendentes da agenda de Doha. Para estes, há quem defenda que, em último caso, podem-se estabelecer acordos plurilaterais a fim de não se prolongar mais a paralisação das negociações.

Há quem defenda o encerramento da Rodada Doha e o início de uma nova rodada que incorpore e corrija os erros da primeira. Outros defendem que Doha deve continuar, pois ainda há muitas negociações sendo feitas. Estes pontos de vista dependem da forma como se vê os avanços de Bali. Aqui, considera-se que a última Conferência Ministerial foi um ponto positivo para a retomada das negociações comerciais e, desta forma, para que se alcancem, progressivamente, os objetivos do sistema multilateral de comércio. 


\section{ABSTRACT}

In a moment of multilateralism crisis, the WTO launched the Doha Round in an attempt to strengthen its trading system. However, the new round began an impasse sequence resulting in the weakening of multilateral trade negotiations. While Doha has innovated in some aspects of its agenda, as the focus on economic and social development of undeveloped countries, its reality is of wide divergence in the negotiations, which have been stalled several times. In an attempt to boost trade, countries have started to look more frequently for bilateral and regional preferential agreements, deteriorating the already weakened multilateralism. The 2007 global financial crisis aggravated this situation. Moreover, the election of a Brazilian for the position of general manager, in 2013, and the achievement relatively successful of the Ministerial Conference in Bali may be the beginning of the reestablishment of Doha. From documentary research, literature review and interviews, this paper seeks to explain how we arrived this situation in multilateral trade routes, listing and discussing its causes and consequences.

Keywords: International Trade; Multilateralism; Doha Round; WTO. 


\section{REFERÊNCIAS}

AZEVÊD0, Roberto. Carta de Genebra. Missão do Brasil em Genebra. Genebra, n. 1, mai. 2009. CAMPOS, Taiane Las Casas. Uma avaliação do efeito institucional sobre o comportamento dos Estados membros da OMC a partir da análise da convergência e divergência nas negociações do Gatt, Gats e Trips. Revista Brasileira de Política Internacional. Brasília, v. 51, n. 2, jul./dez. 2008.

CESAR, Susan Elizabeth Martins. Quais são suas preferências? Breves reflexões sobre a escolha do diretor geral da OMC, o Brasil e o futuro da instituição. Mundorama. Disponivel em: <http://mundorama. net/2013/05/04/quais-sa0-suas-preferencias-breves-reflexoes-sobre-a- escolha-do-diretor-geral-daomc-o-brasil-e-o-futuro-da-instituicao-por-susan-elizabeth- martins-cesar/>. Acessado em: 10 nov. 2013. CESAR, Susan Elizabeth Martins; SATO, Eiiti. A Rodada Doha, as mudanças no regime do comércio internacional e a política comercial brasileira. Revista Brasileira de Política Internacional. Brasília, v. 55, n. 1, p.174-193, 2012.

CRUZ, Sebastião C. Velasco. Estado e mercado: a OMC e a constituição (incerta) de uma ordem econômica global. Revista Brasileira de Ciências Sociais. São Paulo, v. 20, n. 57, fev. 2005. DAMICO, Flavio. A Rodada Doha na encruzilhada. Revista Pontes. Genebra, v. 7, n. 2, jun./jul. 2011.

DELGADO, Nelson. Novas expectativas de retomada da Rodada de Doha da OMC. Será Possivel? E para quê? Observatório de Políticas Públicas para Agricultura. Rio de Janeiro, n. 8, 2007. DOMINGUES, Renato Valladares. A OMC e a geopolíica do comércio internacional. Mundorama. Disponivel em: <http://mundorama.net/2013/05/16/a-omc-e-a-geopolitica-do- comerciointernacional-por-renato-valladares-domingues/>. Acessado em: 10 nov. 2013. JAKOBSEN, Kjeld. 0 divisor de águas da Rodada Doha: um balanço de quase sete anos.

Jornal dos Economistas. Rio de Janeiro, n. 226, mai. 2008, p. 8-11.

LOPES, Inez. 0 fracasso da Rodada Doha. Revista Consilium. Brasília, n. 3, v. 1, jan./abr. 2009. MARTINS, Gilberto de Andrade; THEÓPHILO, Carlos Renato. Metodologia da investigação científica para Ciências Sociais Aplicadas. Editora Atlas, 2009.

MEDEIROS, Moacyr de Franco. Do GATT à OMC - utopia do livre comércio. Disponível em: <https:// www.estacio.br/mestrado/administracao/publicacao/cad_disc ente/arquivo/cad13. pdf> . Acessado em: 02 abr. 2013.

MENEZES, Henrique Zeferino. Crise econômica global e os riscos da escalada do protecionismo para os países em desenvolvimento. Meridiano 47. Brasilia, n. 103, p. 12-15, 2009.

MINISTÉRIO DAS RELAÇ̃̃ES EXTERIORES. Balanço de política externa 2003-2010. Disponível em: <http://www.itamaraty.gov.br/temas/balanco-de-politica-externa-2003- 2010/4.1.2-negociacoescomerciais-omc-rodada-doha. Acessado em: 29 mai. 2014.

NEVES, Victor de Sá. Nova dinâmica nas negociaçães sobre comércio internacional: eleição de Roberto Azevêdo na OMC. Mundorama. Disponivel em: <http://mundor ama.net/2013/07/23/novadinamica-nas-negociacoes-sobre-comercio-internacional-eleicao- de-roberto-azevedo-na-omc-por-victor-desa-neves/>. Acessado em: 10 nov. 2013. 
PECEQUILO, Cristina Soreanu. Manual do Candidato: política internacional. Fundação Alexandre Gusmão. Brasilia: 2012, $2^{a}$ edição.

PONTES. Acordo histórico em Bali dá novo impulso à OMC. Revista Pontes. Genebra, n. 5, dez. 2013.

PONTES. Em Washington, Azevêdo defende liderança dos Estados Unidos na Rodada Doha.

Revista Pontes. Genebra, v. 18, n. 9, mar. 2014.

PRADO, Luiz Carlos Deforme. Negociações comerciais e relações econômicas internacionais: 0 impasse da Rodada de Doha. Revista de Conjuntura. Distrito Federal, n. 31, jul./set. 2007.

PRAZERES, Tatiana Lacerda. A OMC e os blocos regionais. Editora Aduaneiras. São Paulo: 2008. RIBEIRO, Marcos Paulo de Araújo. Rodada Doha: uma análise do estado atual das negociaç̃ões sob a lógica dos jogos de dois níveis. Meridiano 47. Brasilia, n. 80, p. 21-23, 2007.

ROMERO, Rubens de Matos. Acordos regionais de comércio frente ao multilateralismo: as posições do Brasil e do MERCOSUL. $2011.78 \mathrm{f}$. Monografia (Trabalho de conclusão de curso) Instituto de Relaç̃ões Internacionais, Universidade de Brasília, Brasília: 2011.

SATO, Eiiti. Um estalido, e não uma explosão: um epitáfio para a Rodada Doha. Revista Liberdade e Cidadania. Brasília, n. 15, jan./mar. 2012.

THE ECONOMIST. A deadline for Doha. Revista The Economist. Disponível em: <http://www. economist.com/node/18014586? zid=308\&ah=e21d923f9b263c5548d5615da3d3 0f4d >. Acessado em: 26 dez. 2013.

THORSTENSEN, Vera. Os desafios do novo diretor da OMC. Revista Pontes. Genebra, v. 9, n. 5, jun. 2013.

VICKERS, Brendan. A relação entre abordagens plurilaterais e a Rodada Doha. Revista Pontes. Genebra, v. 9, n. 10, 2013.

VIEIRA, Marcelo Milano Falcão; ZOUAIN, Deborah Moraes. Pesquisa qualitativa em administração. Rio de Janeiro: Editora FGV, 2006.

WEBER, Ricardo Basílio. 0 G-20 e os constrangimentos às iniciativas contra hegemônicas no pós Guerra Fria. 2009. 469 f. Tese (Doutorado em Relações Internacionais) - Pontifícia Universidade Católica do Rio de Janeiro, Rio de Janeiro, 2009.

WOJCIECHWSKI, Edna. Do GATT à OMC - Cinquenta anos em busca do livre comércioglobal.

Disponível em:m <http://www.estacio.com.br/mestrado/administracao/publicacao/cad_discente/ arquivo/cad21.pdf> . Acessado em 02 abr. 2013.

WTO. The GATT years: from Havana to Marrakesh. World Trade Organization, 2013. Disponivel em: <http://www.wto.org/english/thewto e/whatis e/tif e/fact4 e.htm> 12/07/201. 